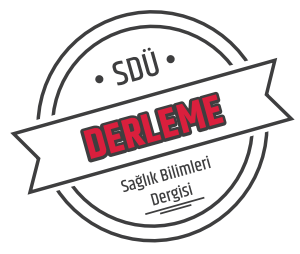

Sdü Sağlık Bilimleri Dergisi / Cilt 10 Sayı 3 / 2019

\title{
Anoreksiya Nervoza Hastalarında Enerji Harcamasının Belirlenmesinde Kullanılan Yöntemler
}

\section{Methods Used to Determine Energy Expenditure in Anorexia Nervosa Patients}

\author{
Tuğba Gündoğduํㅜ, Nilüfer Acar Tek ${ }^{2}$ \\ ${ }^{1}$ SBÜ Antalya Eğitim ve Araştırma Hastanesi, Beslenme ve Diyet Bölümü, Antalya, Türkiye. \\ ${ }^{2}$ Gazi Üniversitesi, Sağlık Bilimleri Fakültesi, Beslenme ve Diyetetik Bölümü, Ankara, Türkiye.
}

\section{Özet}

Anoreksiya nervoza besin k1sitlaması ve diyet enerjisinin azalmasına bağlı olarak patolojik ağırlık kaybı ile sonuçlanan bir psikiyatrik hastalıktır. Bu hastalığa sahip bireylerde tıbbi beslenme tedavisi büyük önem taşımaktadır. Anoreksiya nervoza hastalarında beslenme tedavisinin uygulanmasında, hastayı beslenmeye bağlı oluşabilecek "refeeding" sendromu gibi ciddi komplikasyonlardan korumak için doğru enerji gereksiniminin belirlenmesi önemlidir. Toplam enerji harcamasının önemli bir bileşeni olan dinlenme enerji harcaması (DEH), DEH ölçümünde referans metot olan indirekt kalorimetre ile ölçülebilmektedir. İndirekt kalorimetreye ulaşım mümkün olmadığında enerji harcamasının belirlenmesinde tahmin eşitlikleri klinikte kullanılabilmektedir. Bu eşitlikler arasında çeşitli araştırmalarda geliştirilen; Harris-Benedict, Mifflin, WHO/FAO/UNU, Müller, Owen, Schofield gibi eşitlikler bulunmaktadır. Yapılan çalışma sonuçlarına göre, HarrisBenedict eşitliği DEH'yi referans metoda kıyasla daha fazla tahmin etmektedir. Schebendach eşitliği ise anoreksiya nervozalı adolesanlarda uygulanabilir görünmektedir ve Müller eşitliği DEH ölçümünde kabul edilebilir sonuçlar vermektedir. Ayrıca, beden kütle indeksi 16-18,5 kg/m² arasında olan hastalarda Lazzer eşitliği DEH'yi tahminde iyi sonuçlar vermektedir. Beden kütle indeksi $16 \mathrm{~kg} / \mathrm{m}^{2}$ nin altında olan hastalarda ise DEH'yi doğru tahminde en iyi yüzdeyi veren eşitlikler arasında Huang ve De Lorenzo vardır. Sonuç olarak, günümüzde anoreksiya nervoza hastalarının beslenme tedavisinde enerji gereksinimini belirlemede DEH'nin hesaplanmasında en güvenilir yöntem indirekt kalorimetredir. İndirekt kalorimetreye ulaşılamadığı durumlarda hastanın beden kütle indeksine göre doğruluk oranı yüksek eşitliklerin kullanımı enerji gereksinimini belirlemede kolaylık sağlayabilir.

Anahtar kelimeler: Anoreksiya Nervoza, Beden Kütle İndeksi, Enerji Metabolizması, Tıbbi Beslenme Tedavisi.

\begin{abstract}
Anorexia nervosa is a psychiatric disorder that results in pathological weight loss due to dietary restriction and reduced dietary energy. Medical nutrition therapy is of great importance in individuals with this disease. In the application of nutritional therapy in anorexia nervosa patients, it is important to determine the correct energy requirement to protect the patient from serious complications such as refeeding syndrome which may be caused by feeding. Resting energy expenditure (REE), an important component of total energy expenditure, can be measured by indirect calorimetry, which is the reference method for the measurement of REE. When it is not possible to reach the indirect calorimetry, the estimation equations can be used in the clinic to determine energy expenditure. Among these equations are equations such as Harris-Benedict, Mifflin, WHO/FAO/UNU, Müller, Owen, Schofield developed in various researches. According to the study results, Harris-Benedict equality estimates REE expenditure more than the reference method. Schebendach equality seems to be applicable to anorexia nervosa adolescents, and Müller equality yields acceptable results in the measure of REE. In addition, Lazer equality gives good results in estimating REE in patients with body mass index between $16-18.5 \mathrm{~kg} / \mathrm{m}^{2}$. In patients with a body mass index below $16 \mathrm{~kg} / \mathrm{m}^{2}$, there are Huang and De Lorenzo among the equations that give the best percentage of the correct estimate of REE. In conclusion, the most reliable method for the calculation of REE in determining the energy need for nutritional therapy of anorexia nervosa patients today is indirect calorimetry. The use of highly accurate equations relative to the body mass index of the patient when indirect calorimetry is unavailable can facilitate the determination of energy need.
\end{abstract}

Keywords: Anorexia Nervosa, Body Mass Index, Energy Metabolism, Medical Nutrition Therapy.

aşırı yeme davranışından dolayı diyet enerjisinin azalması ile sonuçlanan ve patolojik ağırlık kaybına neden olan bir psikiyatrik hastalıktır (2). Anoreksiya nervoza; kayg1, depresyon, obsesif-kompulsif bozukluk gibi önemli psikiyatrik komorbid sonuçlar ile ilişkilidir (1). Hastalığın

Yazışma Adresi / Corresponding: Tuğba Gündoğdu,

Antalya Eğitim ve Araştırma Hastanesi, Beslenme ve Diyet Bölümü,

Varlık Mahallesi, Kazım Karabekir Cd., 07100 Muratpaşa / Antalya, Türkiye.

Tel: $02422494400(3349)-05539078238$

E-posta / E-mail: tugbaeroll1@hotmail.com 
etiyolojisi hala belirsiz olmasına rağmen son otuz yıldaki gelişmeler 1şı̆̆ında, genetik faktörlerin anoreksiya nervoza etiyolojisine katkıda bulunduğu belirtilmektedir (3). Genetik faktörlerin ve kalıtımın anoreksiya nervoza etiyolojisinde anlamlı katkısını gösteren ikizlerle ya da aile bazında yapılan çalışmalar dikkat çekmektedir $(4,5)$. Anoreksiya nervoza için kalıtım etkisinin \%28 ile \%74 arasında olduğu tahmin edilmektedir (6). Serotonin reseptörü ve taşıyıcı genlerin (HTR2A ve 5-HTT) tek nükleotid polimorfizmlerinin anoreksiya nervozanın genetik etiyolojisinde rol alan mekanizmalar olduğu düşünülmektedir (3). Ayrıca, yapılan bir çalışmada anoreksiya nervoza ve beden kütle indeksi (BKI) arasında anlamlı bir negatif genetik korelasyon ve anoreksiya nervoza ve şizofreni arasında anlamlı bir pozitif genetik korelasyon olduğu da bildirilmiștir (7).

\section{Tanı}

"Diagnostic and Statistical Manual of Mental Disorders" (DSM-5) anoreksiya nervoza tanı kriterlerini belirtmektedir. Buna göre tanılanacak bireylerde; "A: Gereksinimlerine göre enerji alımını kısıtlamaktadır. Bireyin yaşı, cinsiyeti, gelişimsel olarak izlediği yol ve vücut sağlığı bağlamında belirgin bir biçimde düşük bir vücut ağırlığının olmasına yol açmaktadır. B: Vücut ağırlığı kazanımından ya da şişmanlamaktan çok korkma ve belirgin bir biçimde düşük vücut ağırlığında olmasına karşın vücut ağırlığı kazanımını güçleştiren sürekli davranışlarda bulunmaktadır. C: Bireyin vücut ağırlığını ya da biçimini nasıl algıladığıyla ilgili bir bozukluk vardır, birey kendini değerlendirirken vücut ağırlığı ve biçimine yersiz bir önem yükler, o sıradaki düşük vücut ağırlığının önemini hiçbir zaman kavrayamaz." kriterlerinin varlığı değerlendirilmektedir. Ayrıca, DSM-5'te anoreksiya nervoza hastalığının şiddeti, BKİ değerlerine göre; BKI $\leq 17$ olanlar hafif, 16 ve 16,99 arası orta, 15 ve 15,99 arası şiddetli, 15 'in altı ise aşırı düzey olarak sınıflandırılmıştır (8).

\section{Epidemiyoloji}

Anoreksiya nervoza hastaları ciddi düzeyde zayıftır ve hastalığın bir sonucu olarak bu hastaların fiziksel ve psikolojik fonksiyonları tehditaltındadır(9). Bu hasta grubunun hastanede başlangıçtaki BKİ'leri 11,3 ile 16,2 kg/m² aralığında, mortalite oranları ise \%4 ile \%10 arasında değișiklik göstermektedir (10). Ayrıca, anoreksiya nervozanın psikiyatrik hastalıklar arasında en yüksek mortaliteye sahip olan hastalık olduğu bildirilmektedir (1). Anoreksiya nervoza riski yüksek olan grup 15-19 yaş aralığındaki ergenlerdir (9). Anoreksiya nervoza prevelansının adolesan ve genç yetişkinlerde $\% 2$ ve $\% 3$ kadar yüksek bir oranda seyrettiği rapor edilmiştir (1). Anoreksiya nervoza hastalığında hastaneden taburcu olunduktan 1 yıl sonra hastalığın nüksetme oranı ise $\% 42$ olarak bildirilmiştir (11).

\section{Beslenme Durumu}

Anoreksiya nervoza hastalarının genellikle diyetle yetersiz enerji alımı ile yetersiz makro ve mikro besin öğeleri alımları yaygındır. Adaptif metabolik mekanizmalardan dolayı zamanla yavaş yavaş yeme bozukluğuna bağlı malnütrisyon gelişmektedir (2). Anoreksiya nervoza hastalığında malnütrisyona bağlı somatik komplikasyonlar arasında bradikardi, hipokalemi, hipotansiyon, anemi, hormonal dengesizlik ve osteoporoz sayılabilir. Bilinen bu somatik ve psikiyatrik komplikasyonlar işlevsel kapasiteyi ve yaşam kalitesini ağır olarak etkilemektedir (1). Bu psikiyatrik hastalık ortalama \%71 vücut ağırlığı kaybı ile sonuçlanabilmekte ve sıklıkla kronik stres ile ilişkilendirilmektedir. Medikal sonuçların düzeyi hastalığın devam süresi ile bağlantılı bulunmuştur (12).

\section{Hormonal Değişimler}

Anoreksiya nervoza hastalığı özellikle yetersiz beslenmeye bağlı büyüme hormonuna karşı oluşan bir direnç, düşük leptinemi, yüksek adiponektin ve kortizol seviyeleri, hipotalamik amenore ile ilişkilendirilmiştir. Bu değişikliklerin bir kısmının, uzun süren düşük enerji alımına karşı hayatta kalmak için gerekli adaptif yanıtlar olduğuna inanılmaktadır. $\mathrm{Bu}$ fizyolojik adaptasyonların bazılarının iyileşme için bir engel olabileceği ve anoreksiya nervoza hastalığının tekrarlama riskine katkıda bulunabileceği bildirilmektedir (12).

Leptin düzeyleri yağ kütle ile orantılı olarak zayıf insanlarda daha düşük seviyede olmakla beraber, iki buçuk günlük açlıktan sonra sağlıklı kadınlarda leptin düzeylerinin düştüğü bilinmektedir. Anoreksiya nervoza hastaları, zayıf kadın bireylerle kıyaslandığında; anoreksiya nervoza hastalarında yağ kütle ve leptin seviyelerinin daha düşük olduğu bildirilmiştir. Sağlıklı zayıf bireylerde yağ kütlenin daha fazla olmasının bu durumu açıkladığı düşünülmektedir. Anoreksiya nervoza hastalarında tedaviye başlandıktan birkaç hafta içinde ağırlık kazanımının başlaması ile leptin seviyelerinin yükseldiği bilinmektedir (13). Anoreksiya nervoza hastalarında plazma leptin seviyeleri adipozitenin ölçümü ile pozitif olarak ilişkilendirilmiş ve hastalarda düşük plazma leptin seviyelerinin adipoz doku yetersizliğini yansıttığı bildirilmiştir. Bu durum, leptinin fizyolojik olarak, enerji fazlalığından çok enerji eksikliğinin bir algılayıcısı olarak daha önemli olduğunu gösteren hipotez ile uymaktadır ve leptinin enerji harcamasını azaltarak bir adaptif yanıta sebep olabileceği rapor edilmiştir (14).

Anoreksiya nervoza hastalarında genellikle tiroid uyarıcı hormon (TSH) normal aralıkta iken, total tiroksin (T4) ve triiyodotironin (T3) seviyelerinin düşük olduğu bildirilmiştir. Ayrıca, bu hastalarda, hipotalamik gonadotropin salgılayan hormon (GnRH), luteinleştirici hormon (LH), folikül uyarıcı hormon (FSH), östrojen ve testosteron seviyelerinin de düşük olabildiği bildirilmiştir (15).

\section{Tıbbi Beslenme Tedavisi ve Refeeding Sendromu}

Anoreksiya nervoza hastalarının tıbbi beslenme tedavisinde genelolaraktedavininodaknoktasıhastanınyemealışkanlıkları, vücut ağırlığı ve vücut şekli üzerinedir. Hastalığın tedavisinde özgüven eksikliği, mükemmelliyetçilik, yaşanan travmalar da göz önünde bulundurulmalıdır (9). Hastanede yatarak tedavi gören anoreksiya nervoza hastalarında $0,5-1 \mathrm{~kg} /$ hafta vücut ağırlığı kazanımını başarmak tedavinin hedefleri arasındadır. Ancak bazı hastalar için hastanede tedavi sırasında 1-2 kg/ hafta ağırlık kazanımının da mümkün olabileceği bildirilmiştir. Anoreksiya nervoza hastalarının tıbbi beslenme tedavisinde 
Tablo 1. Dinlenme enerji harcamasının tahmininde yaş, ağırlık ve boy uzunluğu faktörlerini içeren eşitlikler

\begin{tabular}{|c|c|c|c|}
\hline DEH Tahmini için Eşitlik & Birim & Hesaplama için kullanılan faktörler & Kaynak \\
\hline $\begin{array}{l}\text { Erkek: Ağırlıkx13,7516+Boyx5,0033-Yaşx6,7550+66,4730 } \\
\text { Kadın: Ağırlıxx9,5634+Boyx1,8496-Yaşx4,6756+655,0955 }\end{array}$ & $\mathrm{kkal} /$ gün & Cinsiyet, Ağırlık (kg), Boy (cm), Yaş (yıl) & $\begin{array}{c}\text { Harris JA, } \\
\text { Benedict FG, } \\
(22)\end{array}$ \\
\hline 9,99xAğırlık+6,25xBoy-4,92xYaş+166xCinsiyet-161 & $\mathrm{kkal} / \mathrm{gün}$ & Cinsiyet (Erkek: 1, Kadın: 0) & $\begin{array}{l}\text { Mifflin MD, } \\
\text { ve ark. (23) }\end{array}$ \\
\hline $\begin{array}{l}\text { Erkek: Yaş 18-30: 0,063xAğğılık+2,896 } \\
\text { Erkek: Yaş 30-60: 0,048xA ğırlık+3,653 } \\
\text { Erkek: Yaş 60: 0,049xAğırlık+2,459 } \\
\text { Kadın: Yaş 18-30: 0,062xA ğırlık+2,036 } \\
\text { Kadın: Yaş 30-60: 0,034xAğırlık+3,538 } \\
\text { Kadın: Yaş 60: 0,038xAğırlık+2,755 }\end{array}$ & MJ/gün & Cinsiyet, Ağırlık (kg), Yaş (yıl) & $\begin{array}{l}\text { Schofield WN, } \\
\text { (27) }\end{array}$ \\
\hline $\begin{array}{l}\text { Erkek: Ağırlıkx10,2+879 } \\
\text { Kadın: Ağırlıx7,18+795 }\end{array}$ & $\mathrm{kkal} /$ gün & Cinsiyet, Ağırlık (kg) & $\begin{array}{l}\text { Owen OE, } \\
\text { ve ark. }(26)\end{array}$ \\
\hline 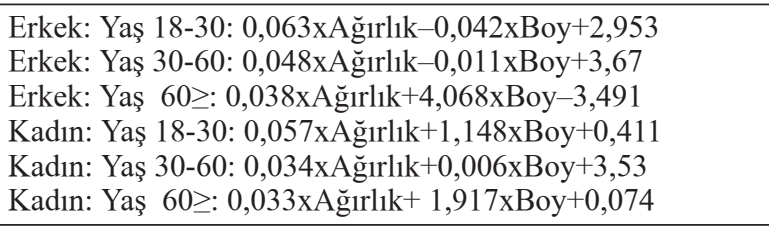 & MJ/gün & Cinsiyet, Ağırlık (kg), Boy (m), Yaş (yıl) & $\begin{array}{c}\text { Schofield WN, } \\
\text { (27) }\end{array}$ \\
\hline $\begin{array}{l}\text { Erkek: Yaş 18-30: 15,3xA ğırlık+679 } \\
\text { Erkek: Yaş 30-60: 11,6xA ğırlık+879 } \\
\text { Erkek: Yaş 60: 13,5xA ğırlık+487 } \\
\text { Kadın: Yaş 18-30: 14,7xA ğırlık+496 } \\
\text { Kadın: Yaş 30-60: 8,7xAğırlık+829 } \\
\text { Kadın: Yaş 60: 10,5xAğırlık+596 }\end{array}$ & $\mathrm{kkal} /$ gün & Cinsiyet, Ağırlık (kg), Yaş (yıl) & $\begin{array}{l}\mathrm{WHO} / \mathrm{FAO} / \\
\mathrm{UNU}(24)\end{array}$ \\
\hline $\begin{array}{l}\text { Erkek: Yaş 18-30: 15,4xAğırlık-27xBoy+717 } \\
\text { Erkek: Yaş 30-60: 11,3xAğırlık-16xBoy+901 } \\
\text { Erkek: Yaş 60: 8,8xAğırlı+1128xBoy-1071 } \\
\text { Kadın: Yaş 18-30: 13,3xAğırlık+334xBoy+35 } \\
\text { Kadın: Yaş 30-60: 8,7xAğırlık-25xBoy+865 } \\
\text { Kadın: Yaş 60: 9,2xAğırlık+637xBoy-302 }\end{array}$ & $\mathrm{kkal} /$ gün & Cinsiyet, Ağırlık (kg), Boy (m), Yaş (yıll) & $\begin{array}{l}\text { WHO/FAO/ } \\
\text { UNU (24) }\end{array}$ \\
\hline 0,047xAğırlık $+1,009 \mathrm{xCinsiyet}+0,01452 \mathrm{x} Y a s ̧+3,21$ & MJ/gün & Ağırlık (kg), Yaş (yıl) & $\begin{array}{l}\text { Müller MJ, } \\
\text { ve ark. }(25)\end{array}$ \\
\hline $\begin{array}{l}\text { Erkek: 53,284xA ğırlık+20,957xBoy-23,859x Yaş }+487 \\
\text { Kadın: 46,322xAğırlık+15,744xBoy-16,66xYaş+944 }\end{array}$ & $\mathrm{Kj} /$ gün & Cinsiyet, Ağırlık (kg), Boy (m), Yaş (yıl) & $\begin{array}{l}\text { De Lorenzo A, } \\
\text { ve ark. (36) }\end{array}$ \\
\hline $\begin{array}{l}\text { Erkek: 0,048xAğğılık+4,655xBoy-0,020xYaş-3,605 } \\
\text { Kadın: 0,042xAğırlık+3,619xBoy-2,678 }\end{array}$ & MJ/gün & Cinsiyet, Ağırlık (kg), Boy (m), Yaş (yıl) & $\begin{array}{l}\text { Lazzer S, } \\
\text { ve ark. (37) }\end{array}$ \\
\hline 10,158xAğırlık+3,933xBoy-1,44xYaş $+273,821$ xCinsiyet $+60,655$ & $\mathrm{kkal} /$ gün & Cinsiyet, Ağırlık (kg), Boy (m), Yaş (yıl) & $\begin{array}{l}\text { Huang } \mathrm{KC} \text {, } \\
\text { ve ark. }(38)\end{array}$ \\
\hline
\end{tabular}

Tablo 2. Dinlenme enerji harcamasının tahmininde yağsız vücut kütlesini içeren eşitlikler

\begin{tabular}{|c|c|c|c|}
\hline DEH Tahmini için Eşitlik & Birim & Hesaplama için kullanılan faktörler & Kaynak \\
\hline $\begin{array}{l}\text { Erkek: 0,08xYVK+0,049xYK-0,019xYaş-2,194 } \\
\text { Kadın: 0,067xYVK+0,046xYK+1,568 }\end{array}$ & MJ/gün & Cinsiyet, YVK ve YK (kg), Yaş (yıl) & $\begin{array}{l}\text { Lazzer S, } \\
\text { ve ark. (37) }\end{array}$ \\
\hline 14,118xYVK+9,367xYK-1,515xYaş+220,863xCinsiyet+521,995 & kkal/gün & Cinsiyet, YVK ve YK (kg), Yaş (yıl) & $\begin{array}{l}\text { Huang } \mathrm{KC} \text {, } \\
\text { ve ark. (38) }\end{array}$ \\
\hline $\begin{array}{l}\text { Erkek: } 22,3 x Y V K+290 \\
\text { Kadın: } 19,7 x Y V K+334\end{array}$ & $\mathrm{kkal} /$ gün & Cinsiyet, YVK (kg) & $\begin{array}{l}\text { Owen OE, } \\
\text { ve ark. (26) }\end{array}$ \\
\hline $19,7 x Y V K+413$ & kkal/gün & YVK $(\mathrm{kg})$ & $\begin{array}{l}\text { Mifflin MD, } \\
\text { ve ark. (23) }\end{array}$ \\
\hline $0,05192 x Y V K+0,04036 x Y K+0,869 x$ Cinsiyet $+0,01181 x Y a s ̧+2,992$ & MJ/gün & Cinsiyet (Erkek: 1 Kadın: 0), YVK ve YK (kg) & $\begin{array}{l}\text { Müller MJ, } \\
\text { ve ark. (25) }\end{array}$ \\
\hline
\end{tabular}


başlangıç enerji gereksinimleri hakkındaki güncel öneriler tutarsızdır. Hastanede yatarak tedavi gören anoreksiya nervoza hastaları için en yaygın uygulamalar uluslararası öneriler doğrultusunda yapılmaktadır ve bu öneriler ölçülü bir düzeyde "refeeding" süreci ile başlamaktadır (16). "Refeeding" sendromu, anoreksiya nervozalı hastaları beslemeye başlanılmasının ilk haftasında meydana gelebilecek metabolik ve klinik bozukluklarla ilişkili potansiyel tehlikelerden kaynaklanmaktadır. Bu potansiyel tehlikeler arasında glikoz metabolizması anormallikleri, serum elektrolitlerindeki değişimler (özellikle düşük düzeydeki fosfat, potasyum ve magnezyum seviyeleri), tiamin eksikliği ile sodyum ve sıv1 tutulması yer alabilmektedir. Eğer bu rahatsılılılar tedavi edilmez ise hastanın hayatını tehdit edebilir ve deliryum ve nöbetler, organ yetmezliği, kardiyak aritmiler ve ani ölüm gibi bir takım komplikasyonlara yol açabilirler. Serum elektrolit düzeylerinin takip edilmesi, durum değerlendirilerek hastaya zamanında suplemantasyon yapılması, bu potansiyel yaşamı tehdit edici sendromun gelişimini önlemek için önemlidir (17). "Refeeding" sendromlu anoreksiya nervoza hastalarına yönelik öneriler değişmekle beraber genel olarak düşük enerjili diyetle başlamayı ve enerji içeriğini yavaş arttırmayı tavsiye etmektedir. Amerika Birleşik Devletleri'nde, günde yaklaşık $1.200 \mathrm{kkal}$ ile başlanıp, her gün yaklaşık $200 \mathrm{kkal}$ kadar arttırılması tavsiye edilirken, Avrupa ve Birleşik Krallık'ta 200-600 kkal gün kadar düşük enerjili bir diyetle beslemeye başlanılması önerilmektedir. Bununla birlikte, bu düşük enerji içeriğine sahip yaklaşımlar son zamanlarda düşük vücut ağırlığı kazanımı ve uzun süreli hastane yatışıyla ilişkilendirilmiş olup ve buna bağlı olarak daha yüksek enerji içerikli ve/veya daha hızlı ilerleme kaydedilecek, yalnızca oral beslenme veya oral ve nazogastrik $(\mathrm{NG})$ beslenmenin kombinasyonunun uygulandığı yeni yaklaşımlar ön plana çıkmaktadır. Bu yaklaşımların, hastanede yakın tıbbi izlemenin mümkün olduğu, hafif ve orta derecede yetersiz beslenmiş hastaları yeniden beslemek için uygun olduğu bildirilmektedir. Ciddi düzeyde yetersiz beslenen ve daha kronik seviyedeki hastalarda ise yavaş ilerlemeli, düşük enerji içeriğini benimseyen yaklaşımları uygulamanın daha doğru olabileceği bildirilmektedir (18).

\section{Enerji Harcaması}

Toplam enerji harcaması (TEH); dinlenme enerji harcaması (DEH) (TEH'nin yaklaşık olarak \%60'1), diyetle-uyarılmış termojenez (TEH'nin yaklaşık olarak \%10'u) ve fiziksel aktiviteyi (TEH'nin yaklaşık olarak \%30’u) içermektedir (19). Anoreksiya nervoza hastalarının DEH'lerinin doğru tahmini klinikte; vücut ağırlığını iyileştirmede gerekli olan diyetin enerji gereksinimini tahmin etmede ve "refeeding" sendromu gibi ciddi komplikasyonları önleyerek beslenmeyi en iyi hale getirmede önemli bir role sahiptir (20). DEH; toplam enerji harcamasına fiziksel aktivite düzeyine göre \%50-75 oranında katkıda bulunmaktadır. DEH; oksijen tüketimini ve karbondioksit üretimini içeren, müdahale gerektirmeyen bir metot olan indirekt kalorimetre ile ölçülebilmektedir. Ancak bu yöntemin kullanımı pahalı olmasından ve eğitimli personele ihtiyaç duyulmasından dolayı kısıtlıdır (21). İndirekt kalorimetreye ulaşımın mümkün olmadığı durumlar için
Harris-Benedict, Mifflin, WHO/FAO/UNU, Müller, Owen, Schofield gibi eşitlikler geliştirilmiştir (22-27). Bu eşitlikler; vücut ağırlığı, uzunluk, yaş, cinsiyet, yağsız kütle, yağ kütlesi, vücut yüzey alanı gibi bağımsız değişkenlerin analizlerini dikkate almaktadır (Tablo 1 ve 2). Ayrıca, etnisitenin DEH tahmininde etkili bir faktör olduğu rapor edilmiştir (28). Ek olarak DEH'nin; metabolik stres, kas tonusu, vücut sıcaklığ1 ve ilaçlardan etkilendiği de bildirilmiştir (21). Yağ kütle ve yağsız kütledeki kayıplar ile düşük vücut ağırlığına sahip olan bir bireyin, normal vücut ağırlığında olan bireyler ile kıyaslandığında; daha düşük düzeyde DEH'ye sahip olduğu bilinmektedir (29). Anoreksiya nervoza gibi hastalıklarda malnütrisyonun gelişmesine bağlı olarak açlığa adaptif yanıt olarak bazal metabolizma hızı (BMH) yavaşlamaktadır ve DEH tahmin edilen değerinin ancak \%50-70'i kadar saptanmaktadır (19). Ayrica zayıf anoreksiya nervoza hastalarında gözlenen nöroendokrin değişiklikler (tiroid hormonları, adrenal hormonlar ve leptin) de düşük düzeydeki DEH'ye katkıda bulunabilmektedir (30).

\section{Anoreksiya Nervozada İndirekt Kalorimetre ve Eşitliklerin Değerlendirilmesi}

Anoreksiya nervoza hastalarının DEH'lerini belirlemede indirekt kalorimetre ölçümü referans metot olarak kabul edilmektedir. Ancak indirekt kalorimetreye ulaşım pahalı olmasından ve eğitimli personele ihtiyaç duyulmasından dolayı her durumda mümkün olmayabilir. Bu nedenle, bazı araştırmacılar çeşitli çalışmalarda indirekt kalorimetreye alternatifolabilecek çeşitli eşitlikler geliştirmeye çalışmışlardır $(31,32)$. Scebendach ve ark., 21 anoreksiya nervoza hastas1 üzerinde yaptıkları bir çalışmada, indirekt kalorimetre ile ölçmüş oldukları DEH'yi, Harris-Benedict eşitliğinin tahminlerinden anlamlı derecede düşük bulduklarını rapor etmişlerdir (31). Ölçülen DEH'yi, eşitlik ile tahmin edilen DEH'nin \%62'si olarak saptamışlardır. Bu yazarlar, klinikte anoreksiya nervoza hastalarının DEH'lerini ölçmek için indirekt kalorimetrenin kullanılamadığı durumlar için bir eşitlik düzeltmesi önermişlerdir. Bu eşitliği; "DEH=1,84(DEH Harris-Benedict)-1435" olarak bildirmişlerdir. Başka bir çalışmada, 13-17 yaş arası 34 adolesan ve 18-30 yaş arası 86 genç kadından oluşan 120 kişilik bir anoreksiya nervoza hastası grubunda, Harris-Benedict eşitliğinin düzeltilmesi ile anoreksiya nervoza hastaları için geliştirilen Schebendach eşitliği, adolesan grupta $\mathrm{BMH}$ ölçümünde doğru tahminler verirken, genç yetişkin grupta indirekt kalorimetre ölçümüne kıyasla daha düşük değerler vermiştir. Schebendach eşitliğinin kadın anoreksiya nervoza hastalarında BMH hesaplamasında çok doğru bir yöntem olmadı $\breve{g ̆}_{1}$ ifade edilen bu çalışmanın sonucunda yeni eşitlikler geliştirilmiştir. Toplam popülasyon, genç yetişkin ve adolesan anoreksiya nervoza grupları için ayrı ayrı geliştirilen eşitlikler sırası ile; "BMH $(\mathrm{kj} /$ gün $)=87 x A$ ğırlık+15,9xYaş", "BMH(kj/gün)=92,8xAğırlık"

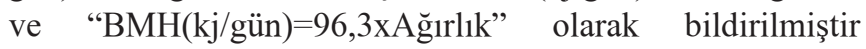
(32).

Anoreksiya nervoza hastası 43 adolesan ve 194 genç-yetişkin olmak üzere iki gruba ayrılan bir popülasyonda, indirekt kalorimetre ile ölçülen $\mathrm{BMH}, \mathrm{WHO} / \mathrm{FAO} / \mathrm{UNU}$, HarrisBenedict, ya da Schebendach eşitliklerinde hesaplanan BMH 
ile kıyaslandığında; WHO/FAO/UNU ve Harris-Benedict eşitliklerinin BMH'yi indirekt kalorimetre ölçümüne kıyasla çok yüksek hesapladığı, Schebendach formülünün kadın adolesanlarda BMH'yi doğru tahminde bulunduğu ve gençyetişkin kadınlarda doğru tahmin etmediği bildirilmiştir (33). Başka bir çalışmada, ortalama yaş 14,7 olan 22 anoreksiya nervoza hastası ile DEH'yi tahmin etmek için kullanılan eşitlikler (Fleisch, Harris-Benedict, FAO, Schofield-HW, Schebendach) indirekt kalorimetre ile yapılan ölçümler ile kıyaslandığında, Schebendach eşitliği haricindeki eşitliklerin DEH'yi indirekt kalorimetre ölçümüne kıyasla daha fazla tahmin ettiği görülmüştür. Schebendach eşitliğinin ise DEH'yi indirekt kalorimetreye kiyasla daha az tahmin ettiği bildirilmiştir (34). Yürütülen bir diğer çalışmada, BKİ'si 18,5 $\mathrm{kg} / \mathrm{m}^{2} \mathrm{nin}$ altında olan 15 zayıf anoreksiya nervoza hastasının kısa dönem "refeeding" sürecinden sonra, "Douglas Bag" metodu ile ölçülen DEH'leri, indirekt kalorimetre ölçümü, Harris-Benedict eşitliği ve Müller eşitliği ile kıyaslanmış ve indirekt kalorimetre ölçümünün ve Müller eşitliğinin DEH'yi doğru tahmin ettiği, Harris-Benedict eşitliğinin ise DEH'yi daha yüksek tahmin ettiği rapor edilmiştir. "Douglas Bag" metodu ile kıyaslandığında; Müller eşitliğinin kabul edilebilir sonuçlar verdiği bildirilmiştir (30). "Douglas Bag" altın standart bir yöntem olduğundan Müller eşitliğinin bu grupta güvenilir olduğu söylenebilir.

Günümüzde, egzersizi izleyen ve spesifik algoritmalar ile indirekt olarak DEH'yi ölçen "SenseWear Pro2 Armband (SWA)" gibi teknolojik araçlar gelişmiştir. "Armband"; çeşitli fizyolojik parametreleri (1sı akışı, deri sıcaklığı, galvanik deri tepkisi, yaklaşık vücut sıcaklığı) ve hareketi izleyen portatif bir cihazdır. Bu cihaz anoreksiya nervoza hasta grubunda yaygın bir davranış olan aşırı düzeydeki egzersizi bildirmesinden dolayı faydalı bulunmaktadır. Ghoch ve ark. (20), anoreksiya nervoza hastalarında SWA'nın DEH'yi belirlemede, indirekt kalorimetre ölçümüne ve Müller eşitliğine bir alternatif olamayacağını bildirmiştir. Bu çalışmaya ek olarak, ortalama BKİ'leri $14,6 \mathrm{~kg} / \mathrm{m}^{2}$ olan 50 kadın anoreksiya nervoza hastası ile yürütülen bir çalışmada, SWA ile değerlendirilen DEH, indirekt kalorimetre ile ölçülen DEH'ye kıyasla \%23 fazla tahmin edilmiştir. Buna karşılık, Müller eşitliği ile değerlendirilen DEH, indirekt kalorimetre ile ölçülen DEH'ye kıyasla \%26 daha az tahmin edilirken; hastalığa özgü geliştirilmiş olan Scalfi denklemi ile değerlendirilen DEH ise indirekt kalorimetre ile ölçülen DEH'ye kıyasla \%5 daha az tahmin edilmiştir. Bu çalışmanın sonucu da anoreksiya nervoza hastalarında DEH'yi tahminde SWA'nın indirekt kalorimetre ile yer değiştirebilir bir metot olmadığını rapor etmektedir (35).

DEH için tahmin eşitliklerinin geçerliliğine bakılan bir çalışmada, BKI'si $16 \mathrm{~kg} / \mathrm{m}^{2}$ nin altında olan hastalarda HarrisBenedict eşitliği hastaların \%39,3'ünde DEH'yi doğru tahmin ederken; hastaların \%51,74'ünde DEH'yi olduğundan fazla tahmin etmiştir. BKİ'si $16-18,5 \mathrm{~kg} / \mathrm{m}^{2}$ arasında olan hastalarda ise Harris-Benedict eşitliğinin hastaların \%51,8'inde DEH'yi doğru tahminde bulunduğu saptanmıştır. Lazzer eşitliği ise hastaların \%60'ından fazlasında DEH'yi doğru tahminde bulunmuştur. BKI'si $16 \mathrm{~kg} / \mathrm{m}^{2}$ nin altında olan hastalarda
DEH'yi doğru tahminde en iyi yüzdeyi veren eşitlikler Huang $(\% 42,7)$ ve De Lorenzo olmuştur. Ayrıca, çalışmada BKI'si $16 \mathrm{~kg} / \mathrm{m}^{2}$ nin altında olan hastalar için literatürdeki eşitliklerin DEH'yi doğru tahmin etmediği ve günümüzde DEH'yi tahminde indirekt kalorimetrenin en uygun yöntem olduğu görüşü bildirilmiştir (21). İranlı 104 zayıf kadında yapılan bir çalışmada, indirekt kalorimetre ölçümü ile ve 10 eşitlik ile tahmin edilen DEH karşılaştırılmıştır. DEH'nin saptanmasında, Müller dişındaki eşitliklerin referans metoda kıyasla DEH'yi anlamlı olarak daha yüksek tahmin ettiği bildirilmiştir. Ancak, Müller eşitliğinin DEH'yi zayıf düzeyde $(\% 54,8)$ kabul edilebilir bir tahminde bulunduğu rapor edilmiştir. $\mathrm{Bu}$ duruma; yetersiz beslenme ve düşük vücut ağırlığına karşı oluşan adaptasyonun, hipometabolik bir durumla sonuçlanmasının neden olabileceği bildirilmiştir (28).

\section{Sonuç}

Anoreksiya nervoza tanısı alan hastalarda tıbbi beslenme tedavisi planlanırken doğru enerji gereksiniminin belirlenmesi, beslenmeye bağlı oluşabilecek komplikasyonlara karşı hastayı korumak için büyük önem taşımaktadır. Bu hasta grubunda DEH'nin belirlenmesinde indirekt kalorimetre referans metot olarak bilinmekle beraber yapılan çalışmalarda DEH ölçümünde indirekt kalorimetreye alternatif olarak tahmin eşitliklerinin de klinikte kullanılabilirliği araştırılmıştır. Harris-Benedict eşitliğinin DEH'yi referans metoda kıyasla daha yüksek tahmin ettiği birçok çalışmada gösterilmiştir. Schebendach eşitliği anoreksiya nervozalı adolesanlarda uygulanmakla beraber, genç yetişkinlerde DEH'yi referans metoda kıyasla daha düşük tahmin etmektedir. Müller eşitliği yağsız vücut kütle ve yağ kütleyi baz aldığı için bazı çalışmalarda DEH ölçümünde kabul edilebilir sonuçlar vermiştir. BKİ'si $16-18,5 \mathrm{~kg} / \mathrm{m}^{2}$ arasında olan hastalarda Lazzer eşitliği DEH'yi tahminde iyi sonuçlar vermektedir. BKI'si $16 \mathrm{~kg} / \mathrm{m}^{2}$ nin altında olan hastalarda ise doğru tahminde en iyi yüzdeyi veren eşitlikler arasında Huang ve De Lorenzo vardır. Sonuç olarak, günümüzde anoreksiya nervoza hastalarının beslenme tedavisinde enerji gereksinimini belirlemede DEH'nin hesaplanmasında en güvenilir yöntem indirekt kalorimetredir. İndirekt kalorimetreye ulaşılamadığ 1 durumlarda hastanın BKI'sine göre doğruluk oranı yüksek eşitliklerin kullanımı enerji gereksinimini belirlemede kolaylık sağlayabilir.

\section{Kaynaklar}

1. Achamrah N, Coëffier M, Rimbert A, Charles J, Folope $\mathrm{V}$, Petit A, et al. Micronutrient status in 153 patients with anorexia nervosa. Nutrients 2017; 9(225): 1-10.

2. Chiurazzi C, Cioffi I, De Caprio C, De Filippo E, Marra $\mathrm{M}$, Sammarco R, et al. Adequacy of nutrient intake in women with restrictive anorexia nervosa. Nutrition 2017; 38: 80-84.

3. Baker JH, Schaumberg K, Munn-Chernoff MA. Genetics of anorexia nervosa. Curr Psychiatry Rep 2017; 19(11): 84.

4. Steinhausen HC, Jakobsen H, Helenius D, Munk-Jørgensen P, Strober M. A nation-wide study of the family aggregation and risk factors in anorexia nervosa over three generations. 
Int J Eat Disord 2015; 48(1): 1-8.

5. Strober M, Freeman R, Lampert C, Diamond J, Kaye W. Controlled family study of anorexia nervosa and bulimia nervosa: evidence of shared liability and transmission of partial syndromes. Am J Psychiatry 2000; 157(3): 393-401.

6. Zipfel S, Giel KE, Bulik CM, Hay P, Schmidt U. Anorexia nervosa: aetiology, assessment, and treatment. Lancet Psychiatry 2015; 2(12): 1099-111.

7. Bulik-Sullivan B, Finucane HK, Anttila V, Gusev A, Day FR, Loh PR, et al. An atlas of genetic correlations across human diseases and traits. Nat Genet 2015; 47(11): 1236-41.

8. American Psychiatric Association. Diagnostic and statistical manual of mental disorders: DSM-5. Washington, DC: American Psychiatric Association; 2013.

9. Berends T, van Meijel B, van Elburg A. The anorexia relapse prevention guidelines in practice: A case report. Perspect Psychiatr Care 2012; 48(3): 149-155.

10. Davies JE, Cockfield A, Brown A, Corr J, Smith D, Munro $\mathrm{C}$. The medical risks of severe anorexia nervosa during initial re-feeding and medical stabilisation. Clin Nutr ESPEN 2017; 17: 92-99.

11. Sansfaçon J, Steiger H, Gauvin L, Fletcher É, Israël M. Does level of motivation for change impact post-treatment outcomes in the eating disorders? Protocol for a systematic review with quantitative analysis. J Eat Disord 2017; 5: 17.

12. Zgheib S, Méquinion M, Lucas S, Leterme D, Ghali $\mathrm{O}$, Tolle $\mathrm{V}$, et al. Long-Term physiological alterations and recovery in a mouse model of separation associated with timerestricted feeding: A tool to study anorexia nervosa related consequences. PLoS One 2014; 9(8): e103775.

13. Hebebrand J, Muller TD, Holtkamp K, HerpertzDahlmann B. The role of leptin in anorexia nervosa: clinical implications. Mol Psychiatry 2007; 12(1): 23-35.

14. Kowalska I, Karczewska-Kupczewska M, Strączkowski M. Adipocytokines, gut hormones and growth factors in anorexia nervosa. Clin Chim Acta 2011; 412(19-20): 170211.

15. Mehler PS, Brown C. Anorexia nervosa - medical complications. J Eat Disord. 2015; 31(3): 11.

16. Marugán de Miguelsanz JM, Torres Hinojal Mdel C, Geijo Uribe MS, Redondo Del Río MP, Mongil López B, De Brito García-Sousa I, et al. Nutritional approach of inpatients with anorexia nervosa. Nutr Hosp 2016; 33(3): 258.

17. Kezelman S, Crosby RD, Rhodes P, Hunt C, Anderson $\mathrm{G}$, Clarke S, et al. Anorexia nervosa, anxiety, and the clinical implications of rapid refeeding. Front Psychol 2018; 4(9): 1097.

18. Garber AK, Sawyer SM, Golden NH, Guarda AS, Katzman DK, Kohn MR, et al. A systematic review of approaches to refeeding in patients with anorexia nervosa. Int J Eat Disord 2016; 49(3): 293-310.

19. Golden NH, Meyer W. Nutritional rehabilitation of anorexia nervosa. Goals and dangers. Int J Adolesc Med Health 2004; 16(2): 131-44.
20. El Ghoch M, Alberti M, Capelli C, Calugi S, Battistini NC, Pellegrini $\mathrm{M}$, et al. Resting energy expenditure assessment in anorexia nervosa: comparision of indirect calorimetry, a multisensor monitör and the Müller equation. Int J Food Sci Nutr 2012; 63(7): 796-801.

21. Jésus P, Achamrah N, Grigioni S, Charles J, Rimbert A, Folope $\mathrm{V}$, et al. Validity of predictive equations for resting energy expenditure according to the body mass index in a population of 1726 patients followed in a Nutrition Unit. Clin Nutr 2015; 34(3): 529-535.

22. Harris JA, Benedict FG. A biometric study of human basal metabolism. Proc Natl Acad Sci USA 1918; 4(12): 370-373.

23. Mifflin MD, St Jeor ST, Hill LA, Scott BJ, Daugherty SA, Koh YO. A new predictive equation for resting energy expenditure in healthy individuals. Am J Clin Nutr 1990; 51(2): 241-247.

24. WHO/FAO/UNU. Energy and protein requirements. Report of a joint FAO/WHO/UNU Expert Consultation. World Health Organ Tech Rep Ser 1985; 724: 1-206.

25. Müller MJ, Bosy-Westphal A, Klaus S, Kreymann G, Lührmann PM, Neuhäuser-Berthold M, et al. World Health Organization equations have shortcomings for predicting resting energy expenditure in persons from a modern, affluent population: generation of a new reference standard from a retrospective analysis of a German database of resting energy expenditure. Am J Clin Nutr 2004; 80(5): 1379-90.

26. Owen OE, Holup JL, D’Alessio DA, Craig ES, Polansky $\mathrm{M}$, Smalley KJ, et al. A reappraisal of the caloric requirements of men. Am J Clin Nutr 1987; 46(6): 875-85.

27. Schofield WN. Predicting basal metabolic rate, new standards and review of previous work. Hum Nutr: Clin Nutr 1985; 39(1): 5-41.

28. Aliasgharzadeh S, Mahdavi R, Asghari Jafarabadi M, Namazi N. Comparison of indirect calorimetry and predictive equations in estimating resting metabolic rate in underweight females. Iran J Public Health 2015; 44(6): 822-829.

29. Dellava JE, Policastro P, Hoffman DJ. Energy metabolism and body composition in long-term recovery from anorexia nervosa. Int J Eat Disord 2009; 42(5): 415-21.

30. El Ghoch M, Alberti M, Capelli C, Calugi S, Dalle Grave R. Resting energy expenditure in anorexia nervosa: Measured versus estimated. J Nutr Metab 2012; 2012: 652932.

31. Schebendach JE, Golden NH, Jacobson MS, Hertz S, Shenker IR. The metabolic responses to starvation and refeeding in adolescents with anorexia nervosa. Ann N Y Acad Sci 1997; 817: 110-9.

32. Scalfi L, Marra M, De Filippo E, Caso G, Pasanisi F, Contaldo $\mathrm{F}$. The prediction of basal metabolic rate in female patients with anorexia nervosa. Int J Obes Relat Metab Disord 2001; 25(3): 359-364.

33. Marra M, Polito A, De Filippo E, Cuzzolaro M, Ciarapica $\mathrm{D}$, Contaldo F. Are the general equations to predict BMR applicable to patients with anorexia nervosa? Eat Weight Disord 2002; 7(1): 53-9. 
34. Cuerda C, Ruiz A, Velasco C, Bretón I, Camblor M, García-Peris P. How accurate are predictive formulas calculating energy expenditure in adolescent patients with anorexia nervosa? Clin Nutr 2007; 26(1): 100-6.

35. Elbelt U, Haas V, Hofmann T, Stengel A, Berger H, Jeran $\mathrm{S}$, et al. Evaluation of a portable armband device to assess resting energy expenditure in patients with anorexia nervosa. Nutr Clin Pract 2016; 31(3): 362-7.

36. De Lorenzo A, Tagliabue A, Andreoli A, Testolin G, Comelli M, Deurenberg P. Measured and predicted resting metabolic rate in Italian males and females, aged 18-59 y. Eur J Clin Nutr 2001; 55(3): 208-14.

37. Lazzer S, Agosti F, Silvestri P, Derumeaux-Burel H, Sartorio A. Prediction of resting energy expenditure in severely obese Italian women. J Endocrinol Invest 2007; 30(1): 20-7.

38. Huang KC, Kormas N, Steinbeck K, Loughnan G, Caterson ID. Resting metabolic rate in severely obese diabetic and nondiabetic subjects. Obes Res 2006; 12(5): 840-5. 